\title{
Campylobacter avium sp. nov., a hippurate-positive species isolated from poultry
}

\author{
Mirko Rossi, ${ }^{1}$ † Lies Debruyne, ${ }^{2}$ Renato Giulio Zanoni, ${ }^{1}$ Gerardo Manfreda, ${ }^{3}$ \\ Joana Revez ${ }^{1}$ and Peter Vandamme ${ }^{2}$ \\ ${ }^{1}$ Department of Veterinary Public Health and Animal Pathology, Alma Mater Studiorum, University \\ of Bologna, Via Tolara di Sopra 50, 40064 Ozzano Emilia, Bologna, Italy \\ ${ }^{2}$ Department of Biochemistry, Physiology and Microbiology, Faculty of Sciences, Ghent University, \\ K. L. Ledeganckstraat 35, B-9000 Gent, Belgium \\ ${ }^{3}$ Department of Food Science, Alma Mater Studiorum, University of Bologna, Via del Florio 2, \\ 40064 Ozzano Emilia, Bologna, Italy
}

Correspondence

Mirko Rossi

mirko.rossi@helsinki.fi

\begin{abstract}
Three strains of an unusual hippurate-positive Campylobacter species were isolated at $37{ }^{\circ} \mathrm{C}$ from caecal contents of broiler chickens and a turkey. All strains were initially identified as Campylobacter by means of genus-specific PCR, but none was further identified using specific PCRs for known thermophilic species. Phylogenetic analyses based on $16 \mathrm{~S}$ rRNA, rpoB and groEL gene sequences revealed that these strains formed a robust clade distinct from other Campylobacter species. Amplified fragment length polymorphism analysis and whole-cell protein electrophoresis were subsequently carried out and confirmed the divergence between the avian strains and other taxa. These data indicate that the unidentified Campylobacter strains belong to a novel taxon which could be distinguished from other campylobacters through its phenotypic and genotypic characteristics. The name Campylobacter avium sp. nov., is proposed for the novel

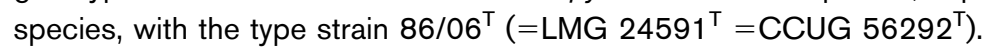

The genus Campylobacter was proposed by Sebald \& Véron (1963). The genus has since been expanded, with species originating from mammals and birds, and now includes 19 species and 6 subspecies (Foster et al., 2004; Vandamme et al., 2005; Inglis et al., 2007; Zanoni et al., 2009). In the present study, we report a polyphasic taxonomic characterization of three unusual hippurate hydrolase-producing Campylobacter strains that were recovered from the caecal contents of poultry.

In the course of bacteriological investigations intended to define the prevalence of Helicobacter pullorum in poultry, seven unusual hippurate-positive Campylobacter isolates

tPresent address: Department of Food and Environmental Hygiene, University of Helsinki, PO Box 66, Agnes Sjöbergin katu 2, FI-00014 Helsinki, Finland.

Abbreviation: AFLP, amplified fragment length polymorphism.

The GenBank/EMBL/DDBJ accession numbers for the 16S rRNA, rpo $B$ and groEL gene sequences of strains $86 / 06^{\top}, 24 / 06$ and 87/06 are respectively EU623473-EU623475 (16S rRNA gene), EU643476, EU643478 and EU643477 (rpoB) and EU636014, EU636013 and EU636812 (groEL).

Neighbour-joining dendrograms based on partial rpoB and groEL sequences and a UPGMA dendrogram based on analysis of protein profiles of strains of Campylobacter avium sp. nov. and other Campylobacter species are available as supplementary material with the online version of this paper. were recovered from caecal contents of six broiler chickens and one turkey originating from three different farms in Italy. Caeca were collected at the slaughterhouse between July and October 2006. Campylobacters were isolated after 3-4 days of incubation at $37{ }^{\circ} \mathrm{C}$ in a microaerobic atmosphere with hydrogen on Brucella sheep blood agar [Brucella broth (BBL) with $1.5 \%$ Bacto agar (Difco) and $5 \%$ sheep blood] using a filter method (Zanoni et al. 2007). The microaerobic atmosphere with hydrogen was obtained by the gas replacement method using an anaerobic gas mixture $\left(10 \% \mathrm{H}_{2}, 10 \% \mathrm{CO}_{2}, 80 \% \mathrm{~N}_{2}\right)$ as described by Bolton et al. (1992). After 3-4 days of incubation on Brucella sheep blood agar, growth appeared as a spreading layer on the agar medium. Single colonies were not seen. Pure cultures were obtained after dilution and repeated subculturing. Following subculturing after $48 \mathrm{~h}$ of incubation at $37{ }^{\circ} \mathrm{C}$, colonies appeared flat, greyish and finely granular with an irregular edge, and showed a tendency to spread along the direction of the streak and to swarm and coalesce. Cells were Gram-negative, sigmoid to allantoid in shape, $1-3 \mu \mathrm{m}$ long and $0.2-0.4 \mu \mathrm{m}$ wide, when observed after Gram staining, and appeared coccoid after $4-5$ days of incubation.

For genotyping analysis, bacterial DNA was extracted by using a ChargeSwitch gDNA Mini Bacteria kit (Invitrogen Life Technologies). 
Isolates were initially identified as Campylobacter jejuni because of their ability to hydrolyse hippurate. To confirm the identification, isolates were further analysed by means of a genus-specific PCR for the genus Campylobacter (Linton et al., 1996) and several species-specific PCRs for different Campylobacter species (Denis et al., 1999; Lawson et al., 1997; Linton et al., 1996). They were confirmed as Campylobacter, but could not be identified at the species level. The diversity among the unidentified Campylobacter isolates was assessed by visual analysis of whole-cell protein profiles in one-dimensional SDS-PAGE, carried out as described by Zanoni et al. (2007). All seven Campylobacter isolates showed almost identical protein profiles (data not shown), suggesting that they belong to the same taxon.

To obtain a more detailed identification, we selected three isolates $\left(86 / 06^{\mathrm{T}}, 87 / 06\right.$ and 24/06) from different hosts (broiler chicken and turkey) and from different regions in Italy, thereby representing a geographically and epidemiologically independent set of isolates.

In order to define the taxonomic position of the avian isolates, a phylogenetic analysis based on 16S rRNA gene sequences was carried out. The nearly complete $16 \mathrm{~S}$ rRNA gene was amplified using universal primers p27f $\left(5^{\prime}-\right.$ AGAGTTTGATCCTGGCTCAG-3') and p1492r (5'TACGGCTACCTTGTTACGACT-5') and the PCR-amplified template was sequenced by primer walking (Primm s.r.l.). Sequences were assembled with Vecton NTI software (Invitrogen) and then aligned in BioEdit (http:// www.mbio.ncsu.edu/BioEdit/bioedit.html) by CLUSTAL w using Campylobacter reference sequences obtained from GenBank. The alignment was adjusted visually removing intervening sequence regions and unknown bases. Finally, data were corrected for multiple base changes by the method of Jukes \& Cantor (1969). A phylogenetic tree was constructed in MEGA3 (http://www.megasoftware.net/) using the neighbour-joining method. Bootstrap analysis was performed with 1000 resampled datasets.

A fragment of approximately $1300 \mathrm{bp}$ of the 16S rRNA gene was obtained. Analysis of the 16S rRNA gene sequences using MEGABLAST (http://www.ncbi.nlm.nih.gov/ BLAST/) indicated that the isolates were most closely related to taxa within the genus Campylobacter, confirming their generic identification. Pairwise comparisons of $16 \mathrm{~S}$ rRNA gene sequences showed that the three isolates were genetically highly related, exhibiting $99.1-99.9 \%$ sequence similarity. Furthermore, the neighbour-joining dendrogram (Fig. 1) indicated that they formed a robust clade (100\% bootstrap support) which was clearly distinct from other Campylobacter species. Pairwise sequence comparisons of $86 / 06^{\mathrm{T}}$ with type strains of the most closely related species revealed similarities of 96.6, 95.5, 94.9 and $94.2 \%$ with Campylobacter upsaliensis, C. helveticus, C. cuniculorum and C. jejuni, respectively.

The phylogenetic relationships of these bacteria were further examined by $r p o B$ (Korczak et al. 2006) and groEL (Kärenlampi et al. 2004) sequence analysis. Sequences were processed as described above. Phylogenetic trees based on partial $r p o B$ and groEL nucleotide sequences are shown in Supplementary Figs S1 and S2 (available in IJSEM Online). In both trees, the unidentified strains clustered together in a tight clade supported by a high bootstrap value $(100 \%)$ and clearly separated from all Campylobacter species. The rpoB sequences of the avian strains were $99-100 \%$ similar, while similarity values towards those of other Campylobacter species varied from 64 to $74.8 \%$. Likewise, pairwise comparisons of the groEL sequences among the avian strains yielded similarity of 99.2$100 \%$, while values towards other Campylobacter species were less than $82.4 \%$. Like Korczak et al. (2006) and Kärenlampi et al. (2004), we observed a good congruence

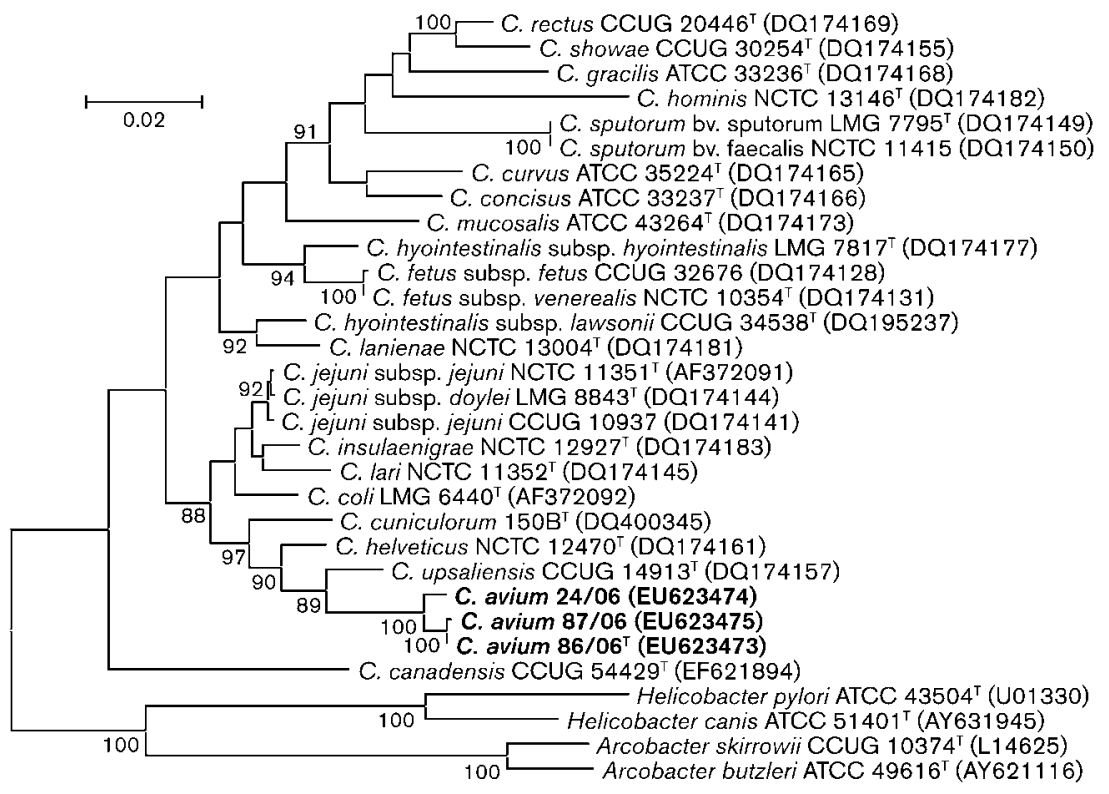

Fig. 1. Unrooted tree, based on $16 \mathrm{~S}$ rRNA gene sequences, showing the phylogenetic relationships of the three strains of $C$. avium sp. nov. Bar, 0.02 nucleotide substitutions per base. Numbers at nodes $(\geqslant 88 \%)$ indicate support for the internal branches within the tree obtained by bootstrap analysis (percentages of 1000 bootstraps). 
between $r p o B$, groEL and $16 \mathrm{~S}$ rRNA gene sequence results, since each of the phylogenetic trees showed a similar topology. However, compared to the $16 \mathrm{~S}$ rRNA gene, $r p o B$ and groEL sequence analyses showed higher resolution as a result of their lower interspecies similarity.

Although all the sequence data demonstrated that the three isolates represented a coherent taxon, amplified fragment length polymorphism (AFLP) analysis and whole-cell protein electrophoresis were performed to further examine the relationships between the strains.

AFLP analysis was performed as described by Debruyne et al. (2009). In brief, $1 \mu \mathrm{g}$ genomic DNA was digested with the HindIII-HhaI restriction enzyme combination. After digestion, site-specific adaptors were ligated to the restriction fragments and primers complementary to the adaptor and restriction site sequence were used in subsequent preselective and selective PCRs. The amplified and fluorescently labelled fragments were loaded on a denaturing polyacrylamide gel on an ABI Prism 377 automated sequencer. GENESCAN version 3.1 (Applied Biosystems) was used for data collection, and the generated profiles were imported, using the CrvConv filter, in BioNumerics version 4.61 (Applied Maths) for normalization and further analysis. Similarity between normalized profiles was determined by Pearson's product-moment correlation coefficient and a UPGMA dendrogram was constructed. Numerical analysis of the AFLP profiles obtained (Fig. 2) differentiated the avian taxon from other Campylobacter species. Moreover, the AFLP profiles of the three strains were all different, thereby demonstrating that the isolates represent different clones.
Whole-cell protein profile analysis was performed using SDS-PAGE as described by Pot et al. (1994). For this analysis, strains were grown microaerobically on Mueller-Hinton agar (Oxoid) supplement with $5 \%(\mathrm{v} / \mathrm{v})$ defibrinated horse blood and incubated microaerobically at $37{ }^{\circ} \mathrm{C}$ for $48 \mathrm{~h}$. Whole-cell protein profiles of Campylobacter reference strains were available from previous studies (Vandamme et al., 1991). Densitometric analysis, normalization and interpolation of the protein profiles, and numerical analysis, were performed using the GelCompar software package (version 4.2; Applied Maths). For whole-cell protein SDS-PAGE analysis, similarity of the obtained normalized SDS-PAGE patterns was determined by Pearson's product-moment correlation coefficient, after which clustering was performed by UPGMA. The dendrogram obtained by numerical analysis of the protein profiles of the three avian strains and of Campylobacter reference strains is shown in Supplementary Fig. S3. The three strains grouped in a single cluster above a similarity level of $94 \%$ and were clearly distinct from the other Campylobacter species.

For the determination of $\mathrm{G}+\mathrm{C}$ content, DNA was enzymically degraded into nucleosides as described by Mesbah \& Whitman (1989). The nucleoside mixture was separated by HPLC using a Waters SymmetryShield C8 column maintained at $37{ }^{\circ} \mathrm{C}$. The solvent was $0.02 \mathrm{M}$ $\left(\mathrm{NH}_{4}\right) \mathrm{H}_{2} \mathrm{PO}_{4}$ (pH 4.0) with $1.5 \%$ acetonitrile. Nonmethylated $\lambda$ phage DNA (Sigma) was used as the calibration reference. The $\mathrm{G}+\mathrm{C}$ content of the DNA of strain $86 / 06^{\mathrm{T}}$ was $35 \mathrm{~mol} \%$. This value is within the range of $28-47 \mathrm{~mol} \%$ reported for genus Campylobacter (Vandamme et al., 2005).

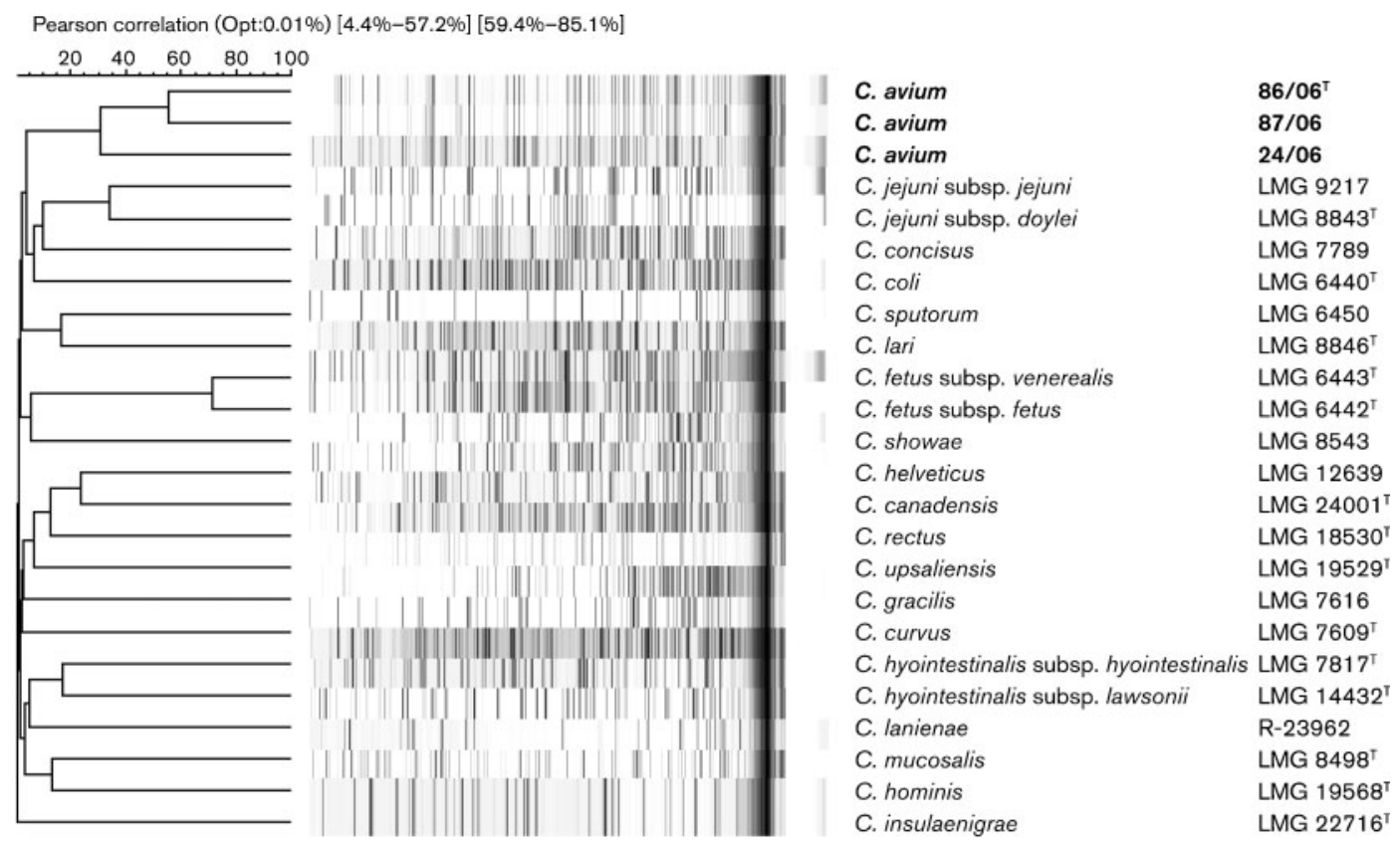

Fig. 2. Dendrogram of the three strains of C. avium sp. nov. based on UPGMA cluster analysis of AFLP profiles. 
Table 1. Phenotypic characteristics of Campylobacter species

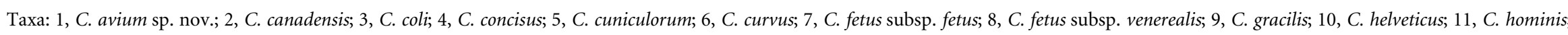

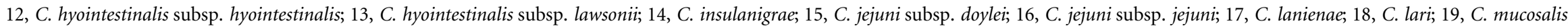

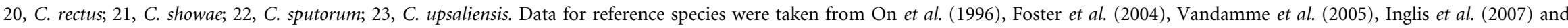

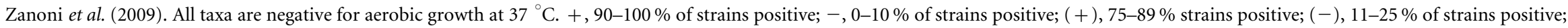
v, 26-74\% of strains positive; w, weakly positive; NA, no data available. CCDA, Charcoal cefoperazone deoxycholate agar (Oxoid); TTC, triphenyl tetrazolium chloride.

\begin{tabular}{|c|c|c|c|c|c|c|c|c|c|c|c|c|c|c|c|c|c|c|c|c|c|c|c|}
\hline Characteristic & 1 & 2 & 3 & 4 & 5 & 6 & 7 & 8 & 9 & 10 & 11 & 12 & 13 & 14 & 15 & 16 & 17 & 18 & 19 & 20 & 21 & 22 & 23 \\
\hline$\alpha$-Haemolysis & - & - & $(-)$ & $(-)$ & + & $(-)$ & - & $\mathrm{V}$ & - & + & $\mathrm{NA}$ & $\mathrm{V}$ & $\mathrm{V}$ & $\mathrm{NA}$ & + & + & + & $\mathrm{V}$ & - & + & + & + & + \\
\hline Oxidase & + & + & + & $\mathrm{V}$ & + & + & + & + & - & + & + & + & + & + & + & + & + & + & + & + & $\mathrm{V}$ & + & + \\
\hline Catalase & w & $\mathrm{V}$ & + & - & + & - & + & $(+)$ & $\mathrm{V}$ & - & - & + & + & + & $\mathrm{V}$ & + & + & + & - & $(-)$ & + & $\mathrm{v}$ & - \\
\hline Alkaline phosphatase & - & - & - & $\mathrm{V}$ & - & $\mathrm{V}$ & - & - & - & - & - & - & $(-)$ & $\mathrm{NA}$ & - & - & + & - & $(+)$ & - & - & - & - \\
\hline$\gamma$-Glutamyltranspeptidase & - & $(+)$ & - & - & - & NA & - & $\mathrm{NA}$ & $\mathrm{NA}$ & - & $\mathrm{NA}$ & - & - & NA & - & - & NA & - & $\mathrm{NA}$ & NA & $\mathrm{NA}$ & - & - \\
\hline Urease production & - & $\mathrm{V}$ & - & - & - & - & - & - & - & - & - & - & - & - & - & - & - & $\mathrm{v}$ & - & - & - & $\mathrm{V}^{*}$ & - \\
\hline Hippurate hydrolysis & + & - & - & - & - & $(-)$ & - & - & - & - & - & - & - & - & + & + & - & - & - & - & - & - & - \\
\hline Indoxyl acetate hydrolysis & + & - & + & - & + & $\mathrm{V}$ & - & - & $\mathrm{V}$ & + & - & - & - & - & + & + & - & - & - & + & - & - & + \\
\hline Nitrate reduction & + & $\mathrm{V}$ & + & $(-)$ & + & + & + & + & $(+)$ & + & - & + & + & + & - & + & + & + & - & + & + & + & + \\
\hline Selenite reduction & - & NA & $\mathrm{v}$ & $(-)$ & - & - & $(+)$ & - & - & - & - & + & + & $\mathrm{NA}$ & - & + & + & + & - & + & + & + & + \\
\hline TTC reduction & - & NA & + & - & $\mathrm{V}$ & $\mathrm{V}$ & - & - & - & - & NA & - & - & $\mathrm{NA}$ & $\mathrm{V}$ & + & $\mathrm{NA}$ & + & - & - & - & - & $\mathrm{V}$ \\
\hline Trace $\mathrm{H}_{2} \mathrm{~S}$ on TSI agar & - & $\mathrm{V}$ & - & - & - & $(-)$ & - & - & - & - & - & + & + & - & - & - & - & - & + & - & $\mathrm{V}$ & + & - \\
\hline \multicolumn{24}{|l|}{ Growth at/in/on: } \\
\hline $25{ }^{\circ} \mathrm{C}$ (microaerobic) & - & - & - & - & - & - & + & + & - & - & - & - & - & - & - & - & - & - & - & - & - & - & - \\
\hline $37^{\circ} \mathrm{C}$ (microaerobic) & + & + & + & + & + & $\mathrm{V}$ & + & + & - & + & + & + & + & + & + & + & + & + & + & - & $\mathrm{V}$ & + & + \\
\hline $42{ }^{\circ} \mathrm{C}$ (microaerobic) & + & + & + & $(+)$ & $(+)$ & $\mathrm{V}$ & $(+)$ & - & $\mathrm{V}$ & + & $(-)$ & + & + & - & - & + & + & + & + & $(-)$ & $\mathrm{V}$ & + & + \\
\hline $37^{\circ} \mathrm{C}$ (anaerobic) & - & + & - & + & - & + & $(-)$ & $\mathrm{v}$ & + & - & + & - & + & - & - & - & + & - & + & + & + & + & - \\
\hline Nutrient agar & - & - & + & $(-)$ & + & + & + & + & + & $(+)$ & $\mathrm{NA}$ & + & + & $\mathrm{NA}$ & + & + & $\mathrm{NA}$ & + & + & $(-)$ & $\mathrm{V}$ & + & + \\
\hline CCDA & - & + & + & $(-)$ & $(+)$ & $(+)$ & + & + & $\mathrm{v}$ & + & $\mathrm{NA}$ & + & + & $\mathrm{NA}$ & + & + & $\mathrm{NA}$ & + & + & - & + & $(+)$ & + \\
\hline MacConkey agar & - & + & $\mathrm{V}$ & - & - & $(+)$ & $(+)$ & $\mathrm{V}$ & $(+)$ & - & - & V & $\mathrm{V}$ & $\mathrm{NA}$ & - & - & + & - & $(+)$ & - & + & V & - \\
\hline $1 \%$ Glycine & - & $\mathrm{V}$ & + & $(-)$ & - & + & + & - & + & V & + & + & V & + & $(-)$ & + & - & + & $\mathrm{V}$ & + & $\mathrm{V}$ & + & + \\
\hline $2 \% \mathrm{NaCl}$ & - & NA & - & $(-)$ & - & $\mathrm{V}$ & - & - & V & - & + & - & - & - & - & - & - & $(+)$ & + & $\mathrm{V}$ & + & + & - \\
\hline $1 \%$ Bile & V & NA & $(+)$ & - & V & - & + & + & - & + & $\mathrm{NA}$ & + & $(+)$ & $\mathrm{NA}$ & + & + & $\mathrm{NA}$ & + & + & - & - & $\mathrm{V}$ & + \\
\hline Requirement for $\mathrm{H}_{2}$ & $\mathrm{~V}$ & - & - & + & - & + & - & - & + & - & + & $\mathrm{V}$ & $\mathrm{V}$ & $\mathrm{NA}$ & - & - & - & - & + & + & + & - & - \\
\hline \multicolumn{24}{|l|}{ Resistance to: } \\
\hline Nalidixic acid & - & $\mathrm{V}$ & - & $(+)$ & $\mathrm{V}$ & + & + & $\mathrm{V}$ & $\mathrm{V}$ & - & $\mathrm{V}$ & + & + & + & - & - & + & $\mathrm{V}$ & $(+)$ & $(+)$ & - & $(+)$ & - \\
\hline Cephalothin & + & - & + & - & $(+)$ & - & - & - & - & - & - & $(-)$ & - & + & - & + & + & + & - & - & - & - & $(-)$ \\
\hline
\end{tabular}


The results of physiological characterization of the three avian strains, determined using standard methods (On \& Holmes, 1991a, b; 1992; Ursing et al., 1994; On et al., 1996), are presented in Table 1 and in the species description. These characteristics allowed differentiation of the poultry strains from established Campylobacter species. Among the hippurate-positive species, the poultry strains can be distinguished from $C$. jejuni subsp. jejuni by their inability to grow in the presence of $1 \%(\mathrm{w} / \mathrm{v})$ glycine and to reduce selenite or triphenyl tetrazolium chloride and from C. jejuni subsp. doylei by their ability to grow at $42{ }^{\circ} \mathrm{C}$ and to reduce nitrate.

In conclusion, the results of this polyphasic taxonomic study indicate that the three strains recovered from caecal contents of poultry represent a unique Campylobacter species for which we propose the name Campylobacter avium sp. nov. Sequence analysis of $r p o B$ and groEL genes and also AFLP and whole-cell protein profile analysis and traditional biochemical analysis allow the novel species to be distinguished from established species.

Campylobacters are the most common bacterial cause of human enteric infections worldwide. Species identification of human isolates is usually carried out in routine clinical microbiology laboratories by means of phenotypic methods. The ability of C. jejuni to hydrolyse hippurate $(\mathrm{N}$ benzoylglycine) to benzoic acid and glycine is commonly used to distinguish it from other Campylobacter species, and only hippurate-negative strains are usually tested by molecular methods (Nakari et al., 2008; Wainø et al., 2003). Nakari et al. (2008) recently standardized the hippurate test by determining cell suspension turbidity limits using C. jejuni and Campylobacter coli reference strains. All strains of $C$. avium sp. nov. were also able to hydrolyse hippurate when tested with the low suspension turbidity described for C. jejuni by Nakari et al. (2008), thus confirming the previous results. Hippurate hydrolase activity in $C$. jejuni is due to the presence of an enzyme encoded by the hipO gene (Hani \& Chan, 1995), and different hipO-based species-specific PCR tests for C. jejuni have been described (Slater \& Owen, 1997; Burnett et al., 2002; Bang et al., 2002). None of these PCRs amplified the hippurate hydrolase gene of C. avium sp. nov. (data not shown). These results suggest that hippurate-positive campylobacters may erroneously be considered as C. jejuni if insufficient biochemical characterization or subsequent molecular confirmation is performed.

\section{Description of Campylobacter avium sp. nov.}

Campylobacter avium (a'vi.um. L. gen. pl. n. avium of birds).

Cells are spiral, Gram-negative rods, motile, $0.2-0.4 \mu \mathrm{m}$ wide and 1-3 $\mu \mathrm{m}$ long. On Brucella sheep blood agar at $37{ }^{\circ} \mathrm{C}$ after $48 \mathrm{~h}$ under microaerobic conditions, colonies appeared non- $\alpha$-haemolytic, flat, greyish and finely granular with an irregular edge and show a tendency to spread along the direction of the streak and to swarm and coalesce. Strictly microaerobic. Able to grow at 37 and $42{ }^{\circ} \mathrm{C}$, but not at $25{ }^{\circ} \mathrm{C}$ or under anaerobic and aerobic conditions. Most strains do not require hydrogen to grow. Oxidase and weak catalase activity are observed, but not urease, $\gamma$-glutamyltranspeptidase or alkaline phosphatase. Strains hydrolyse hippurate and indoxyl acetate and reduce nitrate but not selenite or triphenyl tetrazolium chloride. Strains do not produce $\mathrm{H}_{2} \mathrm{~S}$ in TSI agar. Most strains grow in the presence of $1 \%(\mathrm{w} / \mathrm{v})$ bile. No growth occurs on nutrient agar without blood, on MacConkey agar or in the presence of $1 \%(\mathrm{w} / \mathrm{v})$ glycine or $2 \%(\mathrm{w} / \mathrm{v}) \mathrm{NaCl}$. Growth on charcoal cefoperazone deoxycholate agar (CCDA; Oxoid) appears after $4-5$ days of incubation, and growth on this medium is slightly restricted. Strains are susceptible to nalidixic acid $(30 \mu \mathrm{g})$ and resistant to cephalothin $(30 \mu \mathrm{g})$ by disc diffusion tests. Pathogenicity is unknown.

The type strain is $86 / 06^{\mathrm{T}} \quad\left(=\mathrm{LMG} 24591^{\mathrm{T}}=\mathrm{CCUG}\right.$ $56292^{\mathrm{T}}$ ), which was isolated from a broiler chicken in Italy in 2006. Strains 24/06 (=CCUG 56294) and 87/06 $(=$ LMG $24592=$ CCUG 56293) are also strains of the species. Strains have been recovered from poultry caecal contents.

\section{Acknowledgements}

We thank Dr Jean Euzéby (Laboratoire de Bactériologie, École Nationale Vétérinaire, Toulouse, France) for help with naming the novel species and Professor Valeria Sanguinetti for all the support given.

\section{References}

Bang, D. D., Wedderkopp, A., Pedersen, K. \& Madsen, M. (2002). Rapid PCR using nested primers of the 16S rRNA and the hippuricase (hipO) genes to detect Campylobacter jejuni and Campylobacter coli in environmental samples. Mol Cell Probes 16, 359-369.

Bolton, F. J., Wareing, D. R. A., Skirrow, M. B. \& Hutchinson, D. N. (1992). Identification and biotyping of campylobacters. In Identification Methods in Applied and Environmental Microbiology, pp. 151-161. Edited by R. G. Board, D. Jones \& F. A Skinner. Oxford: Blackwell Scientific.

Burnett, T. A., Hornitzky, A. M., Kuhnert, P. \& Djordjevic, S. P. (2002). Speciating Campylobacter jejuni and Campylobacter coli isolates from poultry and humans using six PCR-based assays. FEMS Microbiol Lett 216, 201-209.

Debruyne, L., On, S. L. W., De Brandt, E. \& Vandamme, P. (2009). Novel Campylobacter lari-like bacteria from humans and molluscs: description of Campylobacter peloridis sp. nov., Campylobacter lari subsp. concheus subsp. nov. and Campylobacter lari subsp. lari subsp. nov. Int J Syst Evol Microbiol 59, 1126-1132.

Denis, M., Soumet, C., Rivoal, K., Ermel, G., Blivet, D., Salvat, G. \& Colin, P. (1999). Development of a m-PCR assay for simultaneous identification of Campylobacter jejuni and C. coli. Lett Appl Microbiol 29, 406-410.

Foster, G., Holmes, B., Steigerwalt, A. G., Lawson, P. A., Thorne, P., Byrer, D. E., Ross, H. M., Xerry, J., Thompson, P. M. \& Collins, M. D. (2004). Campylobacter insulaenigrae sp. nov., isolated from marine mammals. Int J Syst Evol Microbiol 54, 2369-2373. 
Hani, E. K. \& Chan, V. L. (1995). Expression and characterization of Campylobacter jejuni benzoylglycine amidohydrolase (hippuricase) gene in Escherichia coli. J Bacteriol 177, 2396-2402.

Inglis, G. D., Hoar, B. M., Whiteside, D. P. \& Morck, D. W. (2007). Campylobacter canadensis sp. nov., from captive whooping cranes in Canada. Int J Syst Evol Microbiol 57, 2636-2644.

Jukes, T. H. \& Cantor, C. R. (1969). Evolution of protein molecules. In Mammalian Protein Metabolism, vol. 3, pp. 21-132. Edited by H. N. Munro. New York: Academic Press.

Kärenlampi, R. I., Tolvanen, T. P. \& Hänninen, M. L. (2004). Phylogenetic analysis and PCR-restriction fragment length polymorphism identification of Campylobacter species based on partial groEL gene sequences. J Clin Microbiol 42, 5731-5738.

Korczak, B. M., Stieber, R., Emler, S., Burnens, A. P., Frey, J. \& Kuhnert, P. (2006). Genetic relatedness within the genus Campylobacter inferred from $r p o B$ sequences. Int $J$ Syst Evol Microbiol 56, 937-945.

Lawson, A. J., Linton, D., Stanley, J. \& Owen, R. J. (1997). Polymerase chain reaction detection and speciation of Campylobacter upsaliensis and $C$. helveticus in human faeces and comparison with culture techniques. J Appl Microbiol 83, 375-380.

Linton, D., Owen, R. J. \& Stanley, J. (1996). Rapid identification by PCR of the genus Campylobacter and of five Campylobacter species enteropathogenic for man and animals. Res Microbiol 147, 707-718.

Mesbah, M. \& Whitman, W. B. (1989). Measurement of deoxyguanosine/thymidine ratios in complex mixtures by high-performance liquid chromatography for determination of the mole percentage guanine + cytosine of DNA. J Chromatogr 479, 297-306.

Nakari, U.-M., Puhakka, A. \& Siitonen, A. (2008). Correct identification and discrimination between Campylobacter jejuni and C. coli by a standardized hippurate test and species-specific polymerase chain reaction. Eur J Clin Microbiol Infect Dis 27, 513-518.

On, S. L. \& Holmes, B. (1991a). Effect of inoculum size on the phenotypic characterization of Campylobacter species. J Clin Microbiol 29, 923-926.

On, S. L. \& Holmes, B. (1991b). Reproducibility of tolerance tests that are useful in the identification of campylobacteria. J Clin Microbiol 29, $1785-1788$.
On, S. L. \& Holmes, B. (1992). Assessment of enzyme detection tests useful in identification of campylobacteria. J Clin Microbiol 30, 746749.

On, S. L., Holmes, B. \& Sackin, M. J. (1996). A probability matrix for the identification of campylobacters, helicobacters and allied taxa. J Appl Bacteriol 81, 425-432.

Pot, B., Vandamme, P. \& Kersters, K. (1994). Analysis of electrophoretic whole-organism protein fingerprinting. In Chemical Methods in Bacterial Systematics, pp. 493-521. Edited by M. Goodfellow \& A. G. O’Donnell. Chichester: Wiley.

Sebald, M. \& Véron, M. (1963). Teneur en bases de l'ADN et classification des vibrions. Ann Inst Pasteur (Paris) 105, 897-910 (in French).

Slater, E. R. \& Owen, R. J. (1997). Restriction fragment length polymorphism analysis shows that the hippuricase gene of Campylobacter jejuni is highly conserved. Lett Appl Microbiol 25, 274-278.

Ursing, J. B., Lior, H. \& Owen, R. J. (1994). Proposal of minimal standards for describing new species of the family Campylobacteraceae. Int J Syst Bacteriol 44, 842-845.

Vandamme, P., Pot, B. \& Kersters, K. (1991). Differentiation of campylobacters and Campylobacter-like organisms by numerical analysis of one-dimensional electrophoretic protein patterns. Syst Appl Microbiol 14, 57-66.

Vandamme, P., Dewhirst, F. E., Paster, B. J. \& On, S. L. W. (2005). Genus I. Campylobacter Sebald and Véron 1963, 907 ${ }^{\mathrm{AL}}$. In Bergey's Manual of Systematic Bacteriology, 2nd edn, vol. 2, part C, pp. 11471160. Edited by D. J. Brenner, N. R. Krieg, J. T. Staley \& G. M. Garrity. New York: Springer.

Wainø, M., Bang, D. D., Lund, M., Nordentoft, S., Andersen, J. S., Pedersen, K. \& Madsen, M. (2003). Identification of campylobacteria isolated from Danish broilers by phenotypic tests and species-specific PCR assays. J Appl Microbiol 95, 649-655.

Zanoni, R. G., Rossi, M., Giacomucci, D., Sanguinetti, V. \& Manfreda, G. (2007). Occurrence and antibiotic susceptibility of Helicobacter pullorum from broiler chickens and commercial laying hens in Italy. Int $J$ Food Microbiol 116, 168-173.

Zanoni, R. G., Debruyne, L., Rossi, M., Revez, J. \& Vandamme, P. (2009). Campylobacter cuniculorum sp. nov., from rabbits. Int J Syst Evol Microbiol 59, 1666-1671. 